\title{
Citra Visual Koridor Kawasan Kota Lama Semarang Ditinjau dari Potensi Wisata Edukasi Arsitektur Heritage
}

\author{
Eka Virdianti, Septya Ayu Vatrina, Ditia Permata Angkasa, \\ M.Agung Kurnain \\ Jurusan Arsitektur, Fakultas Teknik Sipil dan Perencanaan, Itenas, Bandung \\ Email: virdianti_eka@itenas.ac.id
}

\begin{abstract}
ABSTRAK
Kawasan Kota Lama Semarang pada zaman dahulu merupakan sebuah benteng yang dibangun oleh Kolonial. Perkembangan masa kini beralih menjadi sebuah kawasan dengan beragam fungsi dan memiliki nilai arsitektural yang dikatakan sebagai kawasan cagar budaya. Koridor jalan Letjen Soeprapto merupakan salah satu koridor utama yang memiliki tatanan bangunan yang khas dengan kuantitas yang cukup banyak. Penelitian ini bertujuan untuk menganalisis rancangan koridor jalan Letjen Suprapto di Kawasan Kota Lama Semarang ditinjau dari potensi wisata edukasi arsitektur heritage. Pendekatan penelitian menggunakan kualitatif dengan studi kasus. Pengambilan data melalui observasi, dokumentasi dan wawancara. Metoda analisis digunakan dengan metode deskripsi. Hasil kesimpulan terlihat pemerintah kota Semarang telah melihat potensi wisata yang ada pada Kota Lama Semarang dengan menjadikan "world destination”. Koridor Jl. Letjen Soeprapto dirancang sebagai zona 1-culture sebagai pusat informasi kawasan Kota Lama. Pada koridor Jl. Letjen Soeprapto terdapat 39 bangunan dan 30 merupakan langgam heritage,5 bangunan merupakan high priority buiding. Hal tersebut menjadi potensi dalam wisata edukasi arsitektur heritage khususnya pada aspek visual lingkage, konsep kontras, ornamen langgam yang dapat menjadi wisata dan sumber edukasi arsitektur heritage.
\end{abstract}

Kata kunci: citra visual, potensi wisata edukasi arsitektur, heritage

\begin{abstract}
Kota lama Semarang was once a defensive bastion built by the Colonials. Throughout the years, this area is consisted by buildings with various of functions and is categorized as a cultural and heritage conservation area as its esteemed architectural value. Jalan letjend soeprapto is the main corridor of Kota Lama Semarang and has its own distinctive mass-blocking arrangement with great quantities. This research is purposed to analyse the corridor design of Jl. letjen Soeprapto considered by the potential of heritage architecture educational excursions. This research uses qualitative method and case studies with data compilations of observations, documentations, and interviews, and uses descriptive analysis method. Eventually, the Semarang government has a vision to actualize Kota Lama Semarang as a world tourist destination and design the corridor of jalan letjend soeprapto as the zona 1 - cultural as the information center of Kota Lama Semarang. In the corridor Jl. letjen Soeprapto there were 39 buildings and 30 is a heritage style, the building is a high priority 5 buiding. It became potential in educational excursions architectural heritage, especially the visual aspect Linkage, the concept of contrast, ornamenal style that can be a source of educational exsursions and architectural heritage
\end{abstract}

Keywords: visual image, potential of heritage architecture educational excursions, heritage 


\section{PENDAHULUAN}

Semarang merupakan kota besar di Jawa Tengah yang memiliki peninggalan sejarah. Banyak bangunanbangunan heritage yang tersebar di kota tersebut. Salah satunya. Kawasan Kota Lama Semarang merupakan kawasan heritage peninggalan Belanda yang masih ada dan terkenal di masa sekarang. Namun seiring waktu, perkembangan modernisasi arsitektur dapat mengancam eksistensi kawasan ini. Upaya yang dilakukan pemerintah Indonesia sudah cukup banyak yaitu dengan mengeluarkan undangundang cagar budaya, untuk melindungi karya heritage warisan masa lalu. Hal tersebut tidak cukup, karena peran aktif pemerintahan lokal, masyarakat dan pemangku kepentingan lain adalah motor utama. Diperlukan keterlibatan dan partisipasi masyarakat untuk menjaga kelestarian bangunan warisan sejarah.

Kegiatan pariwisata adalah langkah awal yang paling penting dalam melestarikan bangunan heritage ini, hal tersebut melibatkan banyak pemangku kepentingan dan partisipasi langsung masyarakat. Lebih jauhnya dapat meningkatkan sektor ekonomi, pengembangan/pemberdayaan sosial dan lainnya. Menariknya dalam bidang pendidikan, kegiatan edukasi dapat dilakukan bersamaan dengan kegiatan rekreatif. Sejalan dengan isu tersebut, Pemerintah Kota Semarang pun mengembangkan kawasan Kota Lama Semarang sebagai destinasi wisata dunia, salah satu langkah konkritnya adalah diwujudkannya rencana "Dasar Pengembangan Kawasan Kota Lama Semarang Menjadi Tujuan Wisata Dunia 2018". Berdasarkan pertimbangan tersebut, maka kami mencoba melakukan kegiatan penelitian untuk mengetahui citra visual koridor ditinjau dari potensi wisata edukasi arsitektur di salah satu koridor utama Kota Lama Semarang. Koridor yang akan dipilih adalah Jl. Letjen Suprapto, dimana di koridor tersebut memiliki bangunan dan desain tampilan arsitektur heritage lainnya yang berpotensi sebagai objek wisata edukasi

\section{METODOLOGI}

Citra dalam arsitektur bermakna lebih dalam dari sekedar kegunaan, namun mencerminkan budaya dan karakter manusia yang membangunnya serta menggunakannya. Citra dapat lahir melalui proses diskusi antara arsitek dan kliennya, melalui proses tersebut maka akan tercipta sebuah citra pada bangunan dengan estetika yang dirasakan dari suatu pengalaman ruang [1].

Sebuah karya arsitektur dapat dinikmati dalam sebuah bangunan maupun suatu kawasan. Pada konteks urban disain, pengalaman ruang terbentuk melalui visualisasi kawasan. Dalam membentuk visualisasi kawasan, terdapat kriteria dimana salah satunya adalah manmade element yang merupakan bentukan fisik yang terkait satu sama lain [2]. Kawasan dapat berupa sebuah koridor, citra visual sebuah koridor akan lebih terasa jika terdapat visual lingkage antara façade bangunan eksiting [3]. Keandalan disain kawasan dapat dievaluasi dari dua aspek, terkait penelitian ini adalah historical dan non historical attribute yang dapat diwakili oleh ornamen pada façade [4]. Ornamen yang bersifat historical attribute akan memberikan pengalaman ruang yang berbeda dan akan memberikan identitas kuat pada kawasan jika hal tersebut berulang membentuk visual lingkage.

Identitas tersebut dapat memberikan karakter dan citra yang "khas" pada koridor. Kita mengetahui bahwa beberapa kota besar di Indonesia kaya akan kawasan dengan peninggalan bangunan heritage. Menurut UNESCO, heritage merupakan warisan (budaya) masa lalu, dimana dapat mewakili cerita/sejarah masa lalu yang perlu dikaji atau reinterpretasi untuk kepentingan masa mendatang. Salah satu dari kesepakatan pusaka (heritage) Indonesia adalah pusaka budaya berwujud (tangible) [5].

Koridor Letjen Soeprapto di kawasan Kota Lama Semarang memiliki deretan karya arsitektur heritage dengan langgam/gaya periode colonial dan dapat dikategorikan sebagai kawasan pusaka budaya berwujud. Ciri khas ornamen langgam heritage colonial identik dengan a) gevel (gable) pada tampak depan bangunan; b) tower; c) dormer; d) windwijzer (penunjuk angin); e) nok acroterie (hiasan puncak atap); f) geveltoppen (hiasan kemuncak atap depan); g) ragam hias pada tubuh bangunan; dan h) balustrade [6]. 
Dari ciri khas ornamen tersebut, masyarakat dapat menikmati citra visual koridor tersebut dengan melihat dan mengidentifikasi identitas yang ditimbulkan oleh karya tersebut. Terutama yang berkaitan dan bermakna sejarah serta menginformasikan identitas pada periode heritage tertentu. Dalam pelestarian bangunan heritage, banyak hal yang dapat dilakukan salah satunya adalah kegiatan wisata arsitektur heritage. Tujuan kegiatan ini dapat berdampak kepada penambahan wawasan mengenai warisan karakter sejarah budaya, dan yang terpenting adalah meningkatnya "sense of belonging" karya tersebut di masyarakat sekitar. Dalam konteks pariwisata, sebuah kawasan memiliki potensi sebagai tempat wisata dan menarik untuk dikunjungi oleh wisatawan, harus memiliki tiga kriteria salah satu kriteria adalah "something to see" dimana kawasan tersebut harus terdapat sesuatu yang dapat dinikmati dengan indera penglihatan/visual [7]. Potensi wisata dalam obyek karya Arsitektur dapat ditingkatkan kembali menjadi potensi wisata edukasi Arsitektur. Kita ketahui bahwa konsep dari edukasi adalah belajar dan mengajar, metode pembelajaran dapat berbentuk beragam. Salah satunya dengan metode melihat, mengamati dan menganalisis. Sebuah koridor kawasan dalam kota memiliki penampil visual dari berbagai karya Arsitektur, maka dapat diartikan ada sebuah potensi pembelajaran/edukasi khususnya untuk bidang Arsitektur yaitu dengan melakukan pengamatan dan menganalisis dari sisi visualisasi yang pada akhirnya akan didapatkan simpulan beragam seperti kebudayaan, langgam, keterkaitan dan lainnya. Hal tersebut dapat menjadi sumber edukasi Arsitektur untuk wisatawan sebagai pengunjung umum maupun mahasiswa Arsitektur.

Pendekatan studi yang digunakan dalam penelitian ini adalah dengan metode pendekatan kualitatif melalui studi kasus. Studi kasus dilakukan pada koridor Jl. Letjen Soeprapto, di kawasan Kota Lama Semarang. Koridor ini dipilih dengan pertimbangan jumlah bangunan heritage, sangat dominan dibandingkan koridor lainnya Jalan ini termasuk koridor utama di kawasan Kota Lama Semarang. Pengambilan data dilakukan dengan pengamatan di lapangan, dokumentasi dan wawancara. Proses pengamatan dan dokumentasi lapangan dilakukan pada setiap façade bangunan dan tiap segmen. Pembagian segmen terbagi sisi utara (deretan bangunan bagian utara Jl. Letjen Soeprapto) dan sisi selatan (deretan bangunan bagian selatan Jl. Letjen Soeprapto). Sisi utara dan selatan, masing-masing terdiri dari 5 segmen yang terbagi dari tatanan ruang akibat pola jalan lingkungan, lihat Gambar 1(a) untuk posisi koridor dalam batasan kawasan Kota Lama dan Gambar 1(b) untuk segmen pengambilan samel data.

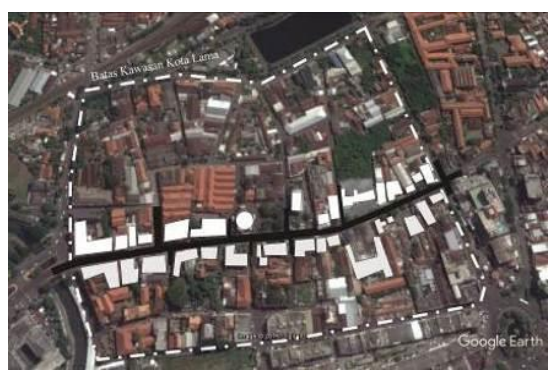

(a)

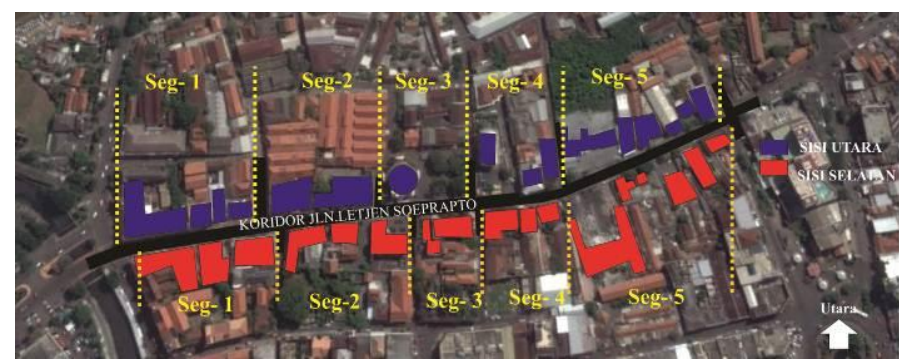

(b)

Gambar 1. (a) Kawasan Kota Lama dan koridor, (b) Segmen pada koridor Jl. Letjen Soeprapto

Data pendukung didapat melalui wawancara dengan pihak terkait khususnya Badan Pengelola Kawasan Kota Lama Semarang (BP2KL). Kisi-kisi penelitian meliputi manmade element terfokus pada ornamen façade. Keseluruhan data dianalisis dengan menggunakan metoda analisis deskriptif. Analisis dilakukan dengan dua tahap yaitu (1) tahap pertama menganalis pada sisi normatif khususnya mengenai rencana pengembangan Kota Lama Semarang; (2) tahap kedua akan dianalisis secara khusus citra visual dari manmade element berupa ornamen yang bersifat historical pada façade bangunan di koridor Jl. Letjen Soeprapto dari sisi potensi wisata arsitektur heritage yaitu visual lingkage dan konsep lainnya. 


\section{HASIL DAN PEMBAHASAN}

Kawasan Kota Lama Semarang telah melalui beberapa fase perkembangan dari zaman kolonial hingga masa sekarang. Dari masa pra benteng (de Vijfhoek van Samarang) hingga periode masa kini yaitu dengan fungsi mix use dan dijadikan kawasan world destination. Pada kawasan tersebut tersebar bangunan dengan langgam arsitektur yang beragam. Langgam heritage yang dapat ditemukan meliputi Vernacular, European influence timber, European influenced mansory, Chinesse, Moorish, Neo classic 19 th, Neo classic 20 th, Art deco, Modern between World War I dan World War II, dan Modern post Independence [8]. Koridor Jln. Letjen Soeprapto merupakan bagian dari kawasan Kota Lama Semarang dimana memiliki bangunan dan desain langgam heritage yang berpotensi sebagai objek wisata edukasi, tersebut antara lain adalah Gereja Blenduk, Restoran Ikan bakar Cianjur, Spiegel Bar and Bistro, Semarang Art Gallery, gedung Jiwasraya, dll. Bangunan-bangunan tersebut memiliki kekhasan dengan memiliki ciri dari arsitektur heritage pada façade bangunannya. Lokasi dan visualisasi koridor Jl. Letjen Soeprapto pada kawasan Kota Lama dapat dilihat pada Gambar 2 untuk sisi utara dan Gambar 3 untuk sisi selatan di bawah ini.

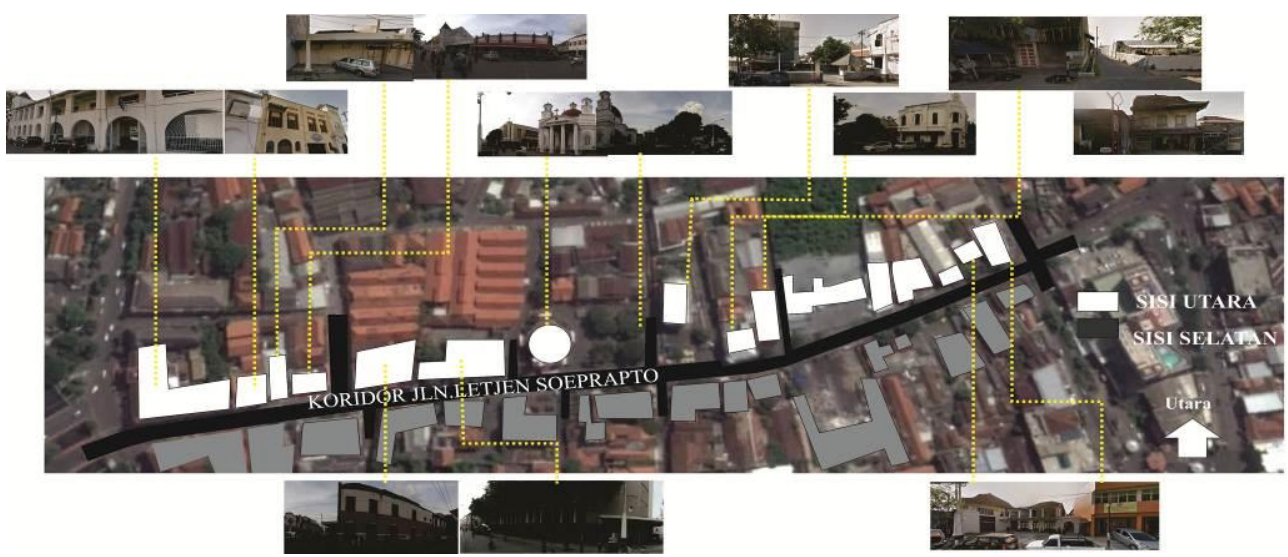

Gambar 2. Visualisasi koridor sisi utara

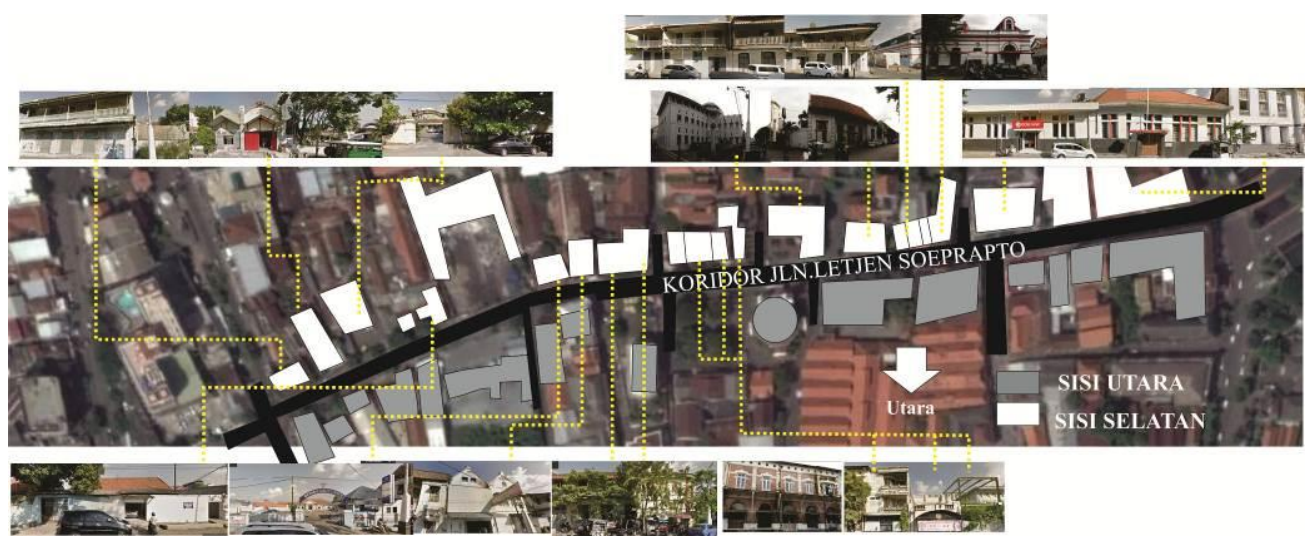

Gambar 3. Visualisasi koridor sisi selatan

Pada Gambar 2 visualisasi citra koridor terbangun dari \pm 16 bangunan dimana 10 bangunan merupakan bangunan heritage dengan periode kolonial. Sisi ini terdiri dari beberapa bangunan ikonik yang sudah terkemuka yaitu bangunan Bank Mandiri, Gereja Blenduk, dan Spiegel, sedangkan pada Gambar 3 merupakan visualisasi citra koridor sisi selatan terdiri dari \pm 23 bangunan meliputi 19 bangunan merupakan bangunan heritage. Pada sisi ini terdapat bangunan ikonik berupa Marba, Jiwasraya, Ikan Bakar Cianjur yang dari sisi arsitektur terlihat ikonik. 


\subsection{Koridor Jln Letjen Soeprapto dalam Pengembangan Kawasan Kota Lama}

Dalam rencana pengembangan kota, kawasan Kota Lama Semarang ditetapkan sebagai world destination pada tahun 2018. Oleh karena itu maka pemerintah mengeluarkan sebuah Grand Design Kawasan Kota Lama 2011 (GDKKLS) disusun oleh Bappeda kota Semarang. Dalam perencanaan tersebut, koridor Jl. Letjen Soeprapto menjadi salah satu dari zona pengembangan disain kawasan. Gambar 2 dan Gambar 3 mendeskripsikan koridor tersebut, memiliki potensi sebagai wisata arsitektur heritage. Dari pertimbangan jumlah bangunan yang mendominasi citra visual merupakan bangunan heritage, pemerintah kota telah mengatur bangunan di kawasan tersebut ke dalam priority building leveling dapat dilihat pada Gambar 4(a). Grand Design Kawasan telah dirancang dengan mengkategorikan koridor Jl. Letjen Soeprapto menjadi zona 1 yaitu zona culture, dapat dilihat pada Gambar 4(b).
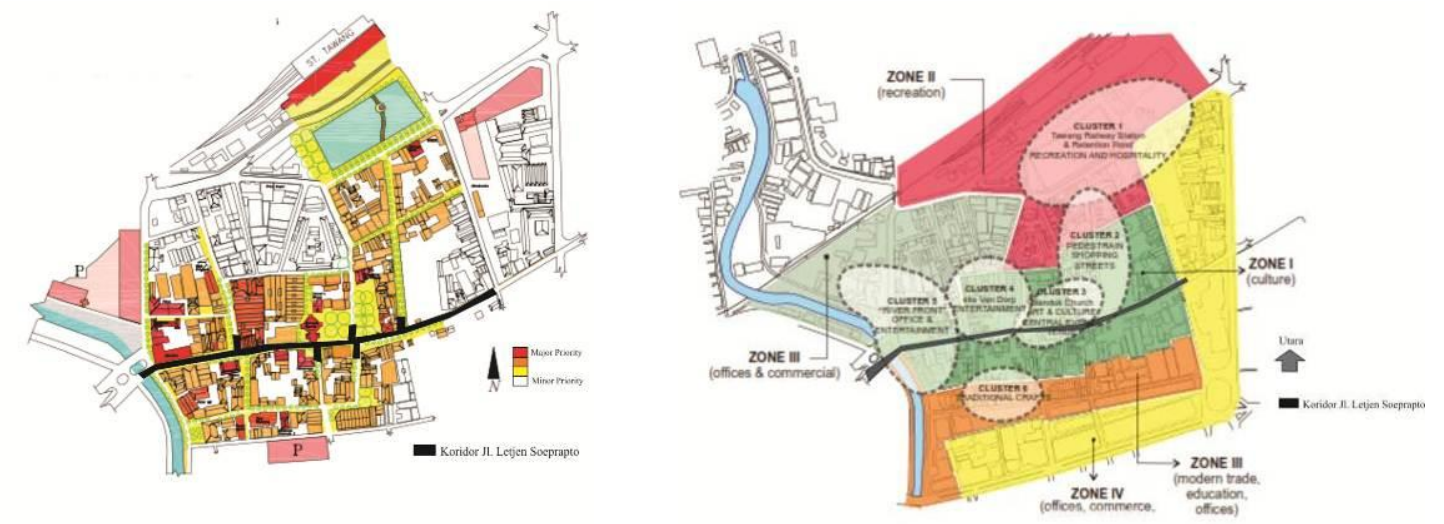

Gambar 4 (a). Priority Building di Kota Lama. (b) Pembagian Zona pada Grand Design Kota Lama (Ertim, 2014)

Berdasarkan data Gambar 4(a) dan Gambar 4(b) di atas maka dalam pembagian sample, koridor ini meliputi segmen sisi utara dan selatan koridor, keseluruhan bangunan pada blok 1-4 merupakan bagian dari bangunan prioritas kawasan Kota Lama, hanya segmen 5 bagian utara yang tidak termasuk bangunan yang diprioritaskan. Pemerintah Semarang berserta BP2KL telah melihat potensi tersebut dan merancang koridor Jl. Letjen Soeprapto sebagai zona 1 yaitu ditetapkan sebagai zona Culture, dimana akan menjadi publik akses dan pusat informasi wisatawan kawasan Kota Lama. Pembagian kluster kawasan dalam Grand Design Kota Lama membagi 6 kluster dimana 4 kluster terdapat pada koridor ini,meliputi riverfront office entertainment, Van Drop Entertainment, Blenduk Church Art \&Culture, Pedesrtrian Shopping [9]. Analisis tersebut menggambarkan bahwa koridor ini sangat berpotensi untuk tujuan wisata utama pada kawasan Kota Lama. Dari aspek partisipasi pemerintah dengan pengembangan/rencana ke depan maka koridor ini memiliki prospek yang menjanjikan dalam konteks pariwisata dan kelangsungan bangunan heritage serta citra visual koridor Jl. Letjen Soeprapto.

\subsection{Citra Visual Manmade Element-Ornamen Façade Koridor Jl. Letjen Soeprapto}

Untuk melihat potensi wisata dari citra visual, maka sebuah koridor perlu memiliki "something to see" [7]. Pada sub bahasan ini, kegiatan analisis akan dilihat dari sisi citra visual arsitektur yaitu berdasarkan elemen kawasan yaitu manmade element [2]. Elemen tersebut difokuskan pada ornamen façade bangunan (attribute) [3]. Analisis akan diproses berdasarkan sampling pembagian sisi utara dan selatan koridor dengan segmen yang telah ditentukan.

\subsubsection{Sisi Utara Koridor Jl. Letjen Soeprapto}

Sisi bagian utara koridor terdapat \pm 16 bangunan, dimana pengelompokan dalam penelitian ini dibagi 5 segmen. Tiap segmen memiliki beberapa façade bangunan sebagai pembentuk citra visual segmen koridor. 


\subsubsection{Segmen 1 Sisi Utara Koridor Jl. Letjen Soeprapto}

Segmen 1 pada sisi utara koridor terdiri atas 3 bangunan yaitu Bank Mandiri KCP Mpu Tantular, Kota Lama Pool \& Resto, dan 3D Trick Art Museum Old City Semarang seperti terlihat pada gambar 5 dibawah ini.

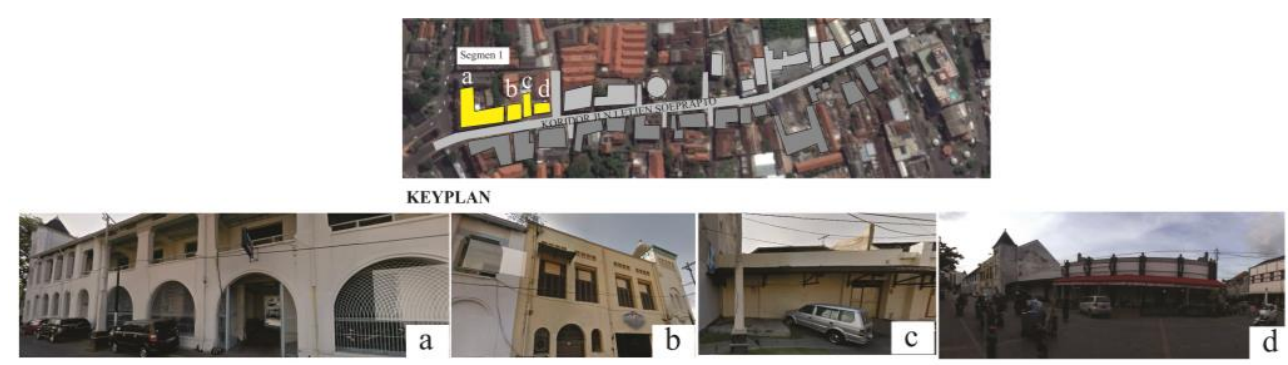

Gambar 5. Visual pada Segmen 1-Sisi Utara Koridor Terbentuk dari Bangunan (a) Bank Mandiri KCP Mpu Tantular, (b) Kota Lama Pool \& Resto, (c) Hunian, (d) 3D Trick Art Museum Old City

Beberapa ornamen pembentuk façade bangunan terlihat terdapat kesamaan yaitu bentuk geometrik sederhana pada façade dibentuk dari arcade bangunan dan jendela serta penegasan elemen vertikal serta horizontal sebagai streamline efect pada bangunan (a), (b), (c) dan (d). Dalam segmen ini secara visual membentuk dua citra yang berbeda yaitu antara bangunan (a) dan (b) serta (c) dan (d). Pada bangunan (a) dan (b), bangunan lebih tinggi dan megah, dimana terdapat menara pada bangunan (a) dan (b) dengan gable, geveltoppe, ballustrade dan nok acroterie. Sedangkan pada bangunan (c) dan (d), bangunan lebih sederhana 1 lantai dengan ornamen teritisan khas indische. Dari segmen ini pengunjung dapat menikmati citra visual yang sama dari sisi bentukan geometrik namun dari sisi arsitektur terlihat detail ornamen yang mencirikan langgam masing-masing bangunan.

\subsubsection{Segmen 2 Sisi Utara Koridor Jl. Letjen Soeprapto}

Segmen 2 koridor ini terdiri atas 2 bangunan yaitu gedung bekas GCT Van Dorp dan PT Perusahaan Perdagangan Indonesia, dapat dilihat pada gambar 6 di bawah ini. Salah satu bangunan dalam segmen ini memiliki fungsi primer dalam rancangan kluster kawasan Kota Lama sebagai Van Drop Entertainment.

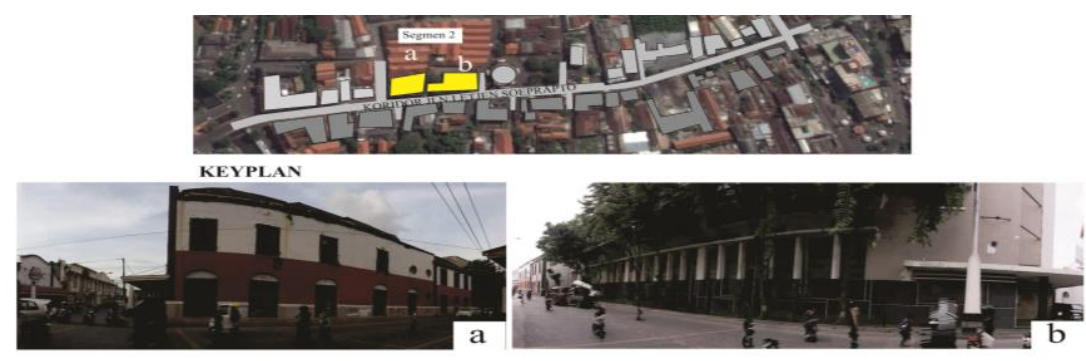

Gambar 6. Visual pada Segmen 2-Sisi Utara Koridor Terbentuk dari Bangunan (a) GCT Van Dorp dan (b) PT Perusahaan Perdagangan Indonesia

Visualisasi segmen ini terbentuk dari dua bangunan dengan ketinggian yang hampir sama. Elemen façade yang mendominasi dan terlihat sama adalah bentuk geometrik dan streamline effect horizontalvertikal, hampir sama dengan visual secara umum pada segmen 1 . Ornamen pada tiap bangunan berbeda secara detail, untuk bangunan (a), façade dibentuk dengan elemen sederhana tanpa hiasan gevel, nok acroterie, geveltoppen dan balustrade. Keunikan bangunan (a) memiliki porthole window. Bangunan (b) pun terbentuk tanpa ragam hias yang detail namun memiliki bentukan menara sederhana serta nok acroterie yang dirancang secara simple. Hal tersebut kemungkinan diakibatkan pengaruh langgam modern dan periode membangun. Dari segmen 2 ini pengunjung dapat menikmati citra visual yang sama dari sisi bentukan geometrik namun dari sisi arsitektur terlihat detail ornamen yang mencirikan langgam masing-masing bangunan dan lebih modern serta unik 


\subsubsection{Segmen 3 Sisi Utara Koridor Jl. Letjen Soeprapto}

Pada segmen 3 sisi utara koridor Jl. Letjen Soeprapto, visual segmen terbentuk dari bangunan tunggal Gereja Blenduk yang merupakan bangunan high priority level building serta merupakan kluster Blenduk Church Art \&Culture. Di sebelah Gereja Blenduk terdapat Taman Srigunting yang merupakan elemen visual penting di koridor ini, selain merupakan tempat terbuka publik dan tempat berkumpul komunitas. Taman ini pada zaman colonial memiliki fungsi sejarah sebagai parade plein untuk panggung parade [10]. Visualisasi segmen 3 dapat dilihat pada Gambar 7.

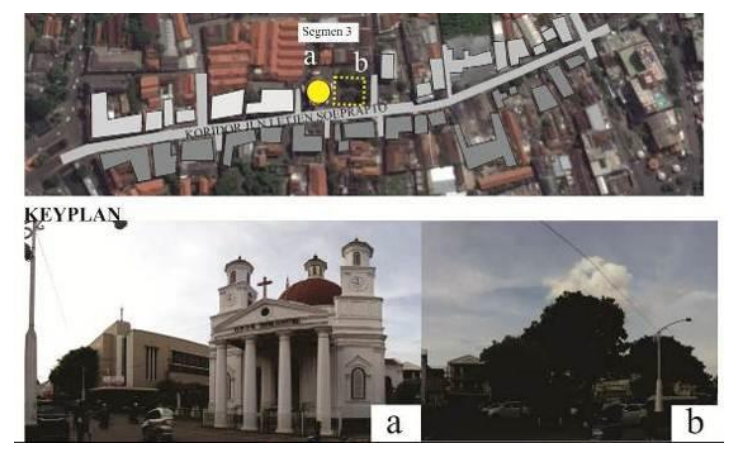

Gambar 7. Visual pada Segmen 3-Sisi Utara Koridor Terbentuk dari Bangunan (a) Gereja Blenduk dan (b) Taman Srigunting.

Bangunan Gereja Blenduk dan Taman Srigunting merupakan bagian jantung koridor Jl. Letjen Soeprapto. Visualisasi segmen ini terbentuk dengan vocal point Gereja Blenduk (a). Bangunan (a) memiliki ornamen façade yang khas berupa atap dome, kolom ionic, pediment, cornice, basilica, dan menara di beberapa. Detail tersebut mencirikan arsitektur langgam neoclassic. Walaupun ornamen tersebut berbeda dengan segmen 1 dan 2 sisi utara namun pada umumnya elemen streamline effect masih mendominasi bagian façade. Taman Srigunting memberikan citra visual elemen alam berupa tanaman bertajuk besar dan perdu, memberikan visualisasi "soft scape" yang memberikan kesan histori. Dari segmen 3 sisi utara, pengunjung dapat menikmati citra visual yang sama dari sisi bentukan geometrik namun dari sisi arsitektur terlihat detail ornamen yang mencirikan neoclassic dan visual softscape.

\subsubsection{Segmen 4 Sisi Utara Koridor Jl. Letjen Soeprapto}

Terdapat 3 bangunan pada segmen 4 sisi utara, yaitu bangunan kantor, Spiegel Bar \& Bistro dan hunian. Visual segmen 4 dapat dilihat pada Gambar 8 di bawah ini.

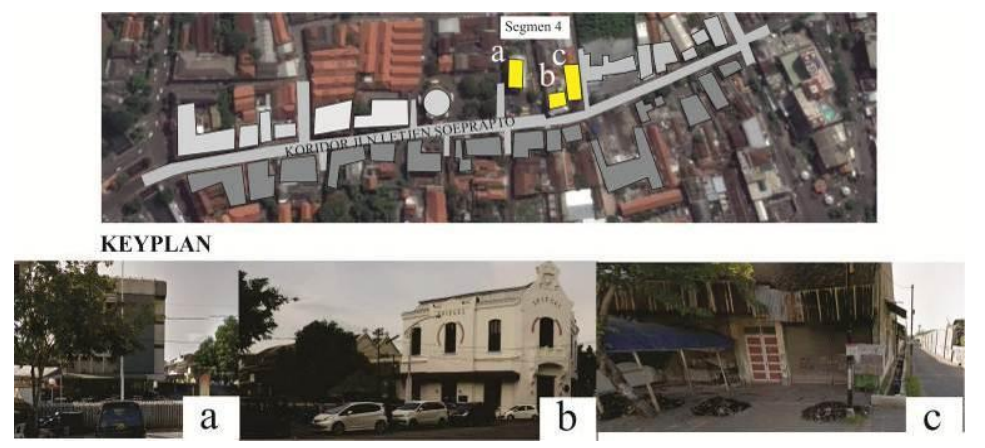

Gambar 8. Visual pada Segmen 4-Sisi Utara Koridor Terbentuk dari Bangunan (a) Bangunan Kantor, Spiegel Bar \& Bistro dan (b) Hunian.

Pada segmen ini citra visual terbentuk secara kontras karena tiga bangunan memiliki ornamen dan ciri bangunan yang berbeda. Bangunan (a) merupakan bangunan modern diluar konteks heritage. Bangunan (b) merupakan bangunan sudut dengan ornamen geometrik dengan gable, dormer, nok acroterie, geveltoppen khas periode kolonial dengan sentuhan indische style pada teritisan. Bangunan (c) berfungsi hunian dengan langgam bercirikan fungsi tersebut. Terlihat dari rancangan pintu, lisplang 
dan atap kemungkinan periode bangunan ini pada saat era Indonesia merdeka (Modern post Independence) karena ornamen mencirikan langgam tersebut. Dari segmen 4 sisi utara, pengunjung dapat menikmati citra visual yang tidak menerus/berlajut karena perbedaan karakteristik ornamen visual tiap bangunan, namun hal tersebut memberikan kontribusi pada bangunan (b) untuk muncul sebagai visual yang bersifat ikonik.

\subsubsection{Segmen 5 Sisi Utara Koridor Jl. Letjen Soeprapto}

Visualisasi segmen 5 sisi utara koridor terdiri atas 6 bangunan yaitu bengkel mobil, bangunan hunian, Teko Deko Koffiehuis, Totabuan Resto, Hotel Raden Patah, dan CV Aneka Diesel, seperti telihat pada Gambar 9.

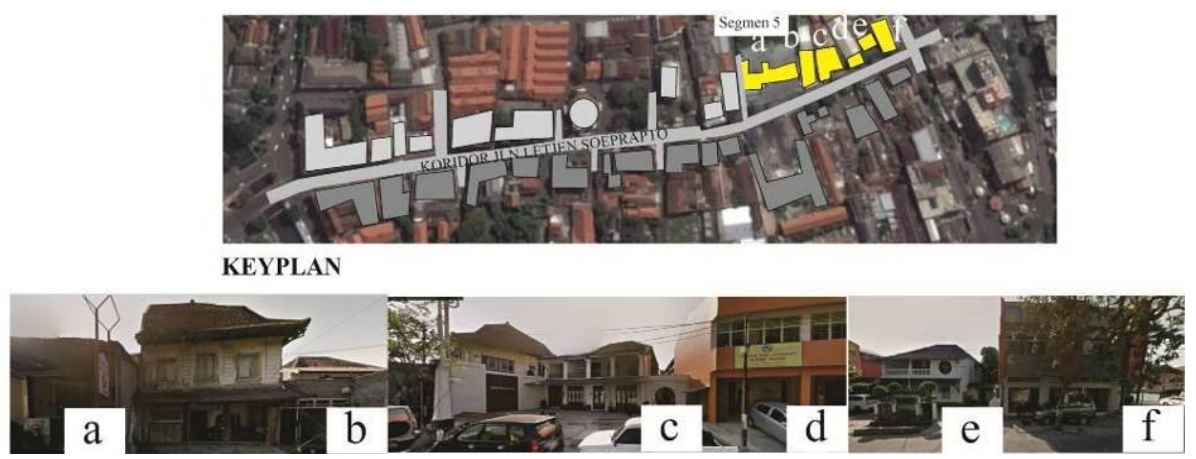

Gambar 9. Visual pada Segmen 9-Sisi Utara Koridor Terbentuk dari Bangunan (a) Bengkel, (b)Bangunan Hunian, (c) Teko Deko Koffiehius, (d) Totabuan Resto, (e) Hotel Raden Patah dan (f) CV Aneka Diesel.

Keragaman ornamen dari 5 bangunan tidak memberikan karakteristik visual lingkage. Hal tersebut karena setiap bangunan memiliki ornamen yang berbeda. Bangunan (a) merupakan bangunan baru. Bangunan (b) adalah bangunan hunian dengan ornamen masih terlihat bentuk geometrik, dan stream line effect pada kolom namun dominasi mencirikan vernacular style. Bangunan (c) merupakan bangunan dengan ornamen kolom ionic, geometrik dan balustrade. Ornamen lain yang mecirikan langgam indische style pada bangunan (c) adalah teritisan dan ornamen dekoratif. Bangunan (d) merupakan bangunan baru dengan langgam modern. Bangunan (e) merupakan hotel dengan tipikan ornamen menyerupai bangunan (c), perbedaan dan keunikannya adalah jendela yang berbentuk porthole. Bangunan (f) memiliki ornamen yang sama dengan bangunan (d) dengan bentuk ornamen sederhana geometrik, mencirikan langgam modern. Dari segmen 5 sisi utara, pengunjung dapat menikmati citra visual yang beragam, ornamen dan langgam yang bervariasi. Namun lebih didominasi dengan visual dari ornamen bangunan modern. Visualisasi koridor yang bersifat kontras memberikan warna tersendiri pada segmen 5 sisi utara untuk dipelajari.

\subsubsection{Sisi Selatan Koridor Jl. Letjen Soeprapto}

Sisi bagian selatan koridor terdapat \pm 23 bangunan, dimana pengelompokan dalam penelitian ini dibagi 5 segmen. Tiap bangunan memiliki ornamen façade yang akan memberikan citra visual sisi selatan koridor.

\subsubsection{Segmen 1 Sisi Selatan Koridor Jl. Letjen Soeprapto}

Segmen 1 pada sisi selatan koridor terdiri atas 3 bangunan yaitu PT Rajawali Nusindo, Kantor Sewa, dan OCBC NISP seperti ada Gambar 10 berikut ini. 


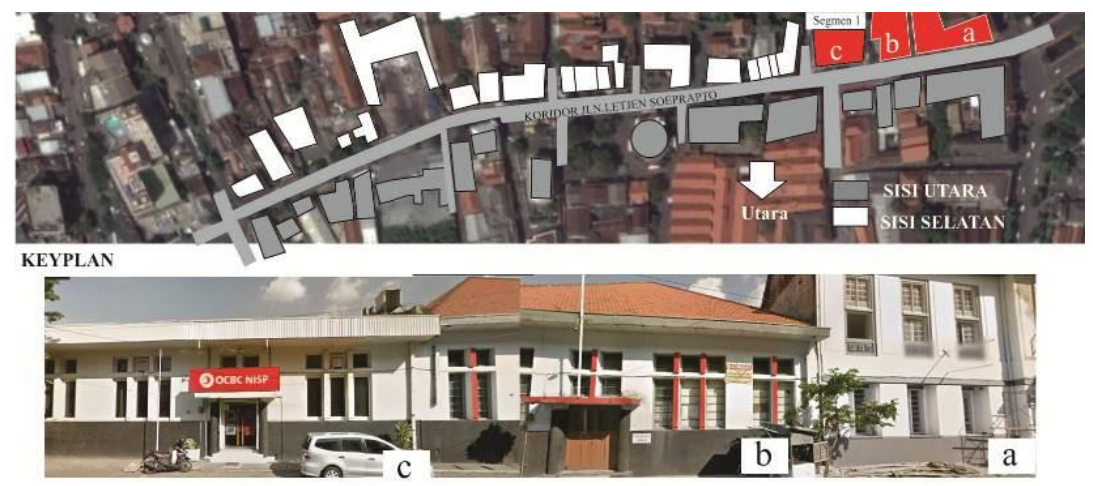

Gambar 10.

Visual pada Segmen 1-Sisi Selatan Koridor Terbentuk dari Bangunan (a) PT Rajawali Nusindo, (b) Kantor Sewa (c) OCBC NISP.

Ornamen pembentuk façade dari 3 bangunan (a), (b), (c) dalam segmen ini, terlihat beberapa kesamaan yaitu bentuk geometrik sederhana dan garis veritikal dan horizontal sebagai streamline effect cirikhas langgam art deco. Bangunan (a) hasil karya Ir. Thomas Karsten yang melebur dengan arsitektur lokal. Bangunan ini memiliki ukuran kusen yang relatif besar dan terdapat kanopi di atasnya. Bangunan (b) bergaya art deco yang dapat terlihat dari bentuk geometrik jendela, dan pengaruh arsitektur local dapat dilihat pada bentuk atap perisai. Bangunan (c) memiliki ornamen dari langgam yang sama dengan bangunan (b), namun dilengkapi dengan flagpole dan beratap datar. Dari segmen ini pengunjung dapat menikmati citra visual lingkage dengan karakter sama dari sisi bentukan geometrik serta streamline.

\subsubsection{Segmen 2 Sisi Selatan Koridor Jl. Letjen Soeprapto}

Pada segmen 2 pada sisi selatan meliputi 5 bangunan yaitu Telkom MSC Area IV Jateng dan DIY, 3 bangunan hunian, Ikan Bakar Cianjur, dan Jiwasraya. Citra. Visualisasi segmen 2 pada koridor sisi selatan ini dapat dilihat Gambar 11. Terdapat 3 bangunan yang merupakan high priority level pada segmen ini, meliputi Telkom MSC karya dari Hulswit dan Cuypers, Ikan Bakar dan Jiwasraya karya Ir. Thomas Karsten.

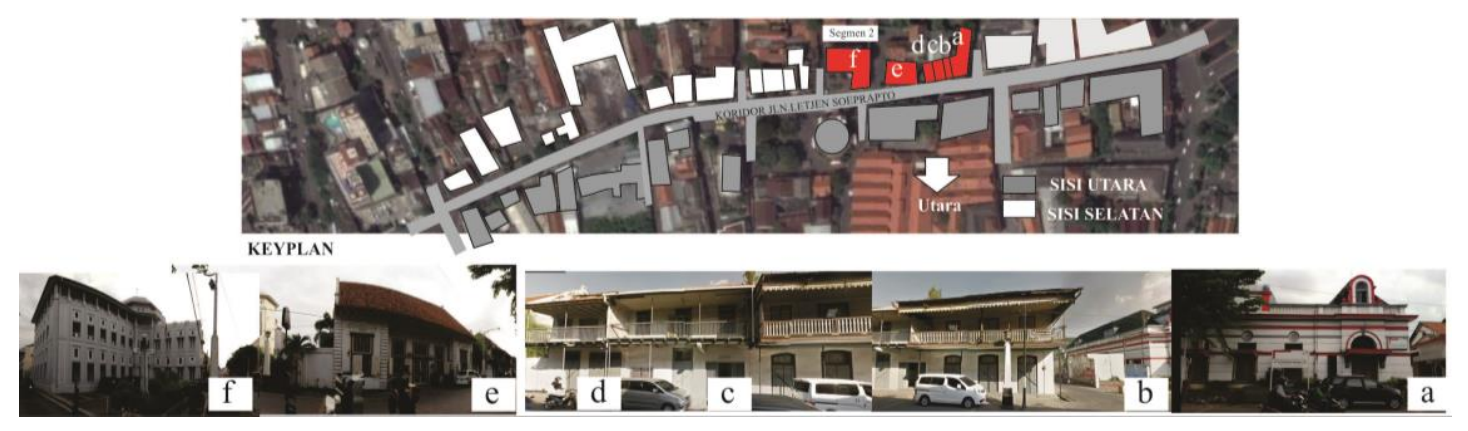

Gambar 11. Visual pada Segmen 2-Sisi Selatan Koridor Terbentuk dari Bangunan (a) OCBC NISP, (b) Hunian, (c) Hunian, (d) Hunian, (e) Ikan Bakar Cianjur, (f) Jiwasraya.

Bangunan (a) dengan ornamen geometrik pada bukaan, gevel serta penggunaan streamline effect horizontal dan vertikal dapat dikatakan berciri langgam art deco. Namun terlihat pengaruh langgam lain dari ornamen porthwindow dan pemakaian atap perisai. Bangunan (b), (c), (d) memiliki langgam yang bersifat kontras dengan bangunan (a) ornamen (b), (c), (d) merupakan bangunan hunian dengan visual saling terkait, yaitu terdapat teras, ornamen geometrik, balustrade, hiasan dan bentuk atap pelana. Dari ornamen tersebut dapat diidentifikasi bahwa 3 bangunan tersebut berlanggam indische. Visualisasi langgam indische Bangunan ini memiliki keterkaitan langgam bangunan (d), dilengkapi ornamen geometrik, streamline effect, gable, nok acroteire, windwijer dan pengaruh arsitektur lokal pada atap berbentuk pelana dan kanopi. Ornamen pada bangunan (e) memiliki karakter langgam art deco dengan 
bentuk ornamen geometrik, streamline effect, serta kaca patri. Dari 5 bangunan pada segmen 2 sisi selatan terbentuk citra visual yang memiliki kesamaan dari ornamen geometrik dan streamline. Konsep kontras terlihat dengan adanya perbedaan penerapan ornamen bangunan (b), (c), (d) yang mencirikan langgam yang berbeda dari bangunan lain. Hal ini dapat diakibatkan oleh periode waktu membangun dan fungsi bangunan yang berbeda.

\subsubsection{Segmen 3 Sisi Selatan Koridor Jl. Letjen Soeprapto}

Terdapat 4 bangunan pada segmen 3 sisi selatan meliputi bangunan baru, Sate dan Gulai Kambing 29, Hunian-Toko serta Gedung Marba. Dari 4 bangunan tersebut membentuk citra visual segmen dimana visualisasi segmen ini dapat dilihat pada Gambar 12.

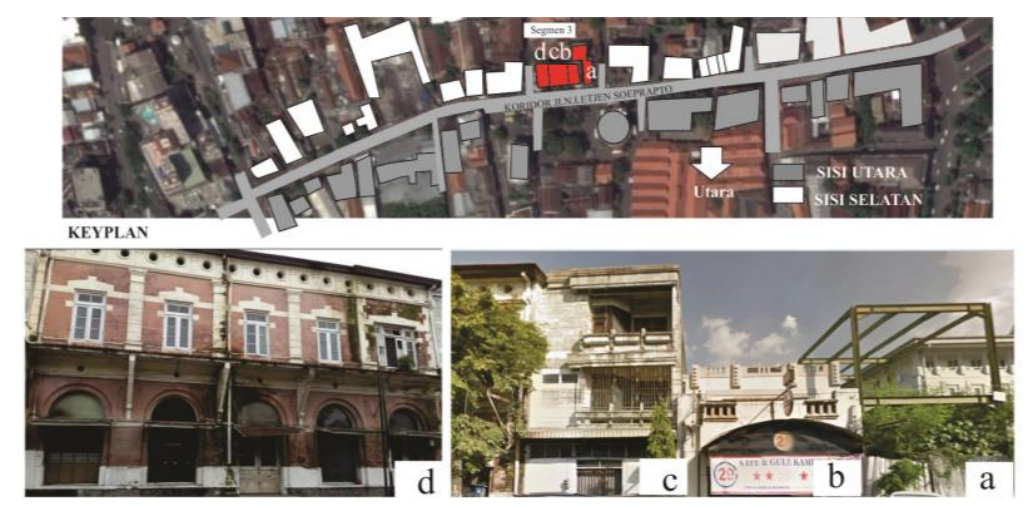

Gambar 12. Visual pada Segmen 3-Sisi Selatan Koridor Terbentuk dari Bangunan (a) Bangunan Baru, (b) Sate Kambing Gulai 29, (c) Hunian-Toko, (d) Gedung Marba

Citra visual segmen ini terbentuk dari bangunan (b), (c), (d) dimana terdapat ornamen berbentuk geometris dan penggunaan streamline effect. Ornamen bangunan (b) dan (c) memiliki karakter yang sama, hanya bangunan (b) lebih ekspresif dengan adanya penggunaan bentuk arch serta balustrade yang lebih dekoratif. Bangunan (d) memiliki ornamen pediment, bentuk arch dan detail cornice, dimana penerapan ornamen tersebut terdapat pada langgam neoclassical. Pada segmen 3 sisi selatan koridor lebih banyak memberikan citra visual lingkage bila dilihat dari ragam ornamen yang dominan dengan bentuk yang sama.

\subsubsection{Segmen 4 Sisi Selatan Koridor Jl. Letjen Soeprapto}

Visualisasi segmen 4 sisi selatan terbentuk dari 4 yaitu meliputi Soroban Mental Aritmatika Indonesia, Toko, Gudang, dan Hunian yang dapat dilihat pada Gambar 13 di bawah ini.
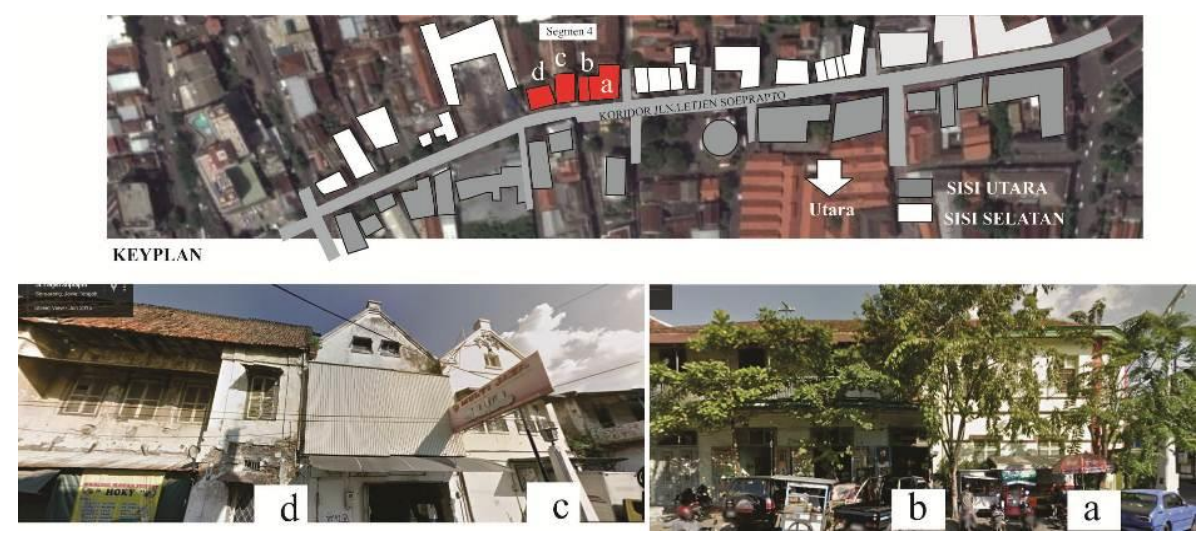

Gambar 13. Visual pada Segmen 4-Sisi Selatan Koridor Terbentuk dari Bangunan (a) Bangunan Soroban Mental Aritmatika Indonesia, (b) Toko, (c) Gudang, (d) Hunian 
Bangunan (a), (b), (c) dan (d) memiliki kesamaan penggunan bentuk ornamen yang akhirnya membentuk visual lingkage segmen. Kesamaan itu terbentuk datei dominasi penggunaan ornamen geometrik dan masih terdapat streamline effect namun tidak terlalu tegas. Dari penerapan atap pelana, kanopi, teritisan dapat diidentifikasi visualisasi terbentuk dari bangunan berlanggam indische. Perbedaan terdapat dari beberapa detail ornamen lainnya sebagai contoh ornamen gabble pada bangunan (c).

\subsubsection{Segmen 5 Sisi Selatan Koridor Jl. Letjen Soeprapto}

Pada segmen 5 sisi selatan terbentuk dari 6 yaitu meliputi Satlantas Semarang, Asrama Polisi, Hunian, Satlantas Semarang, Hunian dan Bangunan Bekas De Zikel \& Co. Visualisasi segmen ini dapat dilihat pada Gambar 14.
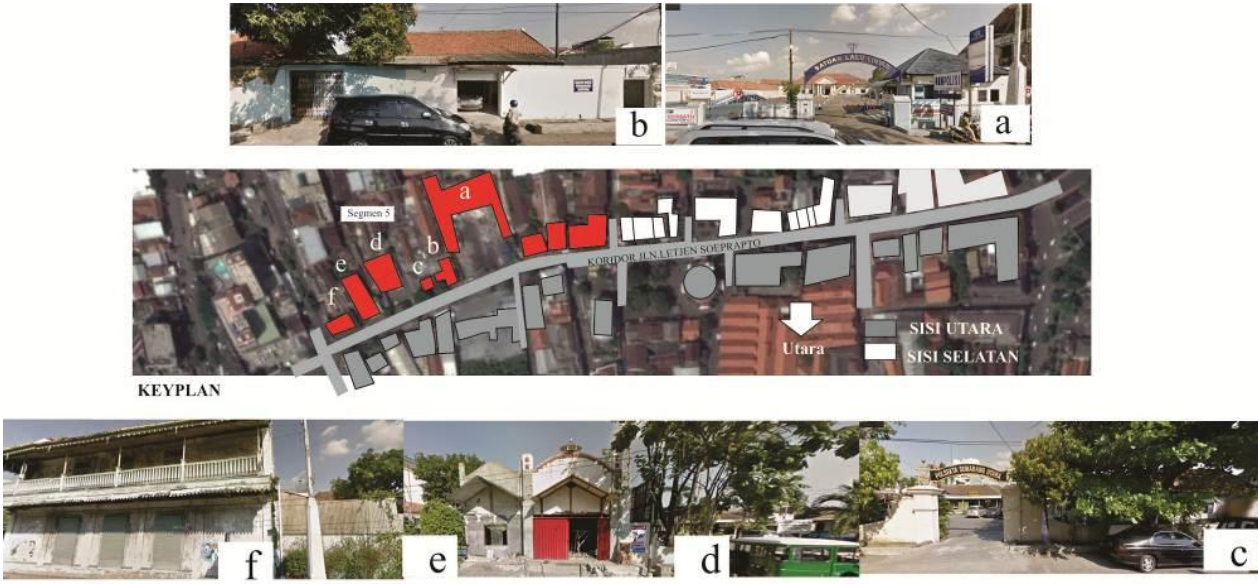

Gambar 14. (a) bangunan bekas De Zikel \& Co, (b) rumah, (c) Polsekta Semarang, (d) asrama polisi, (e) Satlantas Semarang

Pada segmen ini banyak terdapat bangunan yang telah mengalami perubahan dan ornamen tidak mencirikan arsitektur heritage khususnya bangunan (a) dan (c). Namun ornamen arsitektur bergaya local periode tertentu dapat dilihat pada bangunan (b) dan (e). Bangunan (f) merupakan bangunan heritage dengan ornamen geometrik, balustrade, atap pelana yang merupakan ciri langgam indische. Dari segmen 5 ini, pengunjung dapat menikmati citra visual yang beragam, kesan kontras, perbedaan antara bangunan periode modern dan lama. Visualisasi koridor yang bersifat kontras memberikan warna tersendiri pada koridor.

\subsection{Citra Visual Koridor Jl. Letjen Soeprapto Sebagai Potensi Wisata Edukasi Arsitektur Heritage}

Konsep wisata dapat berupa wisata edukasi, merupakan konsep wisata yang bersifat pengayaan yang bersifat rekreatif. Pada obyek karya Arsitektur, kegiatan ini dapat ditingkatkan kembali menjadi potensi wisata edukasi Arsitektur. Kita ketahui bahwa konsep dari edukasi adalah belajar dan mengajar, metode pembelajaran dapat berbentuk beragam. Salah satunya dengan metode melihat, mengamati dan menganalisis. Sebuah koridor kawasan dalam kota memiliki penampil visual dari berbagai karya Arsitektur, maka dapat diartikan ada sebuah potensi pembelajaran/edukasi khususnya untuk bidang Arsitektur yaitu dengan melakukan pengamatan dan menganalisis dari sisi visualisasi yang pada akhirnya akan didapatkan simpulan beragam seperti kebudayaan, langgam, keterkaitan dan lainnya. Hasil analisis di atas, koridor ini sangat berpotensi untuk dijadikan wisata edukasi arsitektur dan sumber edukasi. Hal tersebut dapat dilihat dari sisi visual lingkage koridor dari dominasi penerapan ornamen bentuk geometrik dan streamline effect. Konsep kontras secara visual akibat penerapan ornamen dan langgam arsitektur. Koridor ini dapat dipandang sebagai museum arsitektur heritage kawasan Kota Lama karena dari \pm 39 bangunan di koridor hanya \pm 9 bangunan merupakan langgam modern. Berbagai langgam hetritage dapat dipelajari di koridor ini, walaupun untuk penilaian secara detail mengenai langgam perlu penelitian lebih lanjut. 


\section{SIMPULAN}

Dalam pengembangan kawasan koridor Jl. Letjen Soeprapto dirancang sebagai zona 1-culture tempat pusat informasi kawasan Kota Lama. Terdapat 6 kluster pengembangan, 4 diantaranya ada pada koridor ini. Artinya pemerintah telah menempatkan koridor ini sebagai kawasan potensial wisata. Pada aspek citra visual, di Jl. Letjen Soeprapto terdapat 39 bangunan dan 30 merupakan langgam heritage, 5 bangunan merupakan high priority buiding. Hal tersebut dapat menjadi potensi dalam wisata edukasi dan sumber edukasi arsitektur heritage. khususnya pada aspek visual lingkage, konsep kontras, ornamen langgam.

\section{DAFTAR PUSTAKA}

[1] Hanisch, Ruth (2006). "Absolutely Fabulous!: Architecture \& Fashion" dalam Fontine, Terry (2008) "Citra Brand Melalui Citra Arsitektur". pada lib.ui.ac.id/file?file=digital/125573R050842 diakses 4Februari 2017

[2] Berry, Wendell (1980). Good Neighbors, Building Next to History: Design Guidelines Handbook "dalam Jurnal Langkau Betang, "Misavan dan Gultom "Karakter Visual kawasan Jalan Tanjungpura Pontianak". Vol. 1/No. 2/2014

[3] Hedman,R and Jaszewski, A (1985). Fundamentals of Urban Design. APA, Washington D.C, pp 9 .

[4] Brolin, Brent C (1980). Architecture In Context Fitting New building With Old. Van Nostrand Reinhold Company, New York,pp 153

[5] Pusat Pelestarian Pusaka Indonesia (2003). Piagam Pusaka Indonesia. Universitas Gajah Mada

[6] Handinoto. (1996). Perkembangan Kota dan Arsitektur Kolonial Belanda di Surabaya 18701940. Diterbitkan atas Kerja Sama Lembaga Penelitian dan Pengabdian Kepada Masyarakat Universitas Kristen Petra Surabaya dan Penerbit Andi

[7] Yoeti, O, (1997). Perencanaan dan Pengembangan Pariwisata", dalam Fiatiano, "Tata Cara Mengemas Produk Pariwisata pada Daerah Tujuan Wisata", Jurnal Unair "Masyarakat Kebudayaan dan Politik". Tahun XXI, Nomor 4, Oktober-Desember 2008, pp 164

[8] Abieta, at.al. (2015). Carring For Your Heritage Building, Building Owner Information. UNESCO Jakarta.

[9] Ertim LSM (2014). Boekoe Pinter Kota Lama,Kawasan Kota Lama City of The Past. City of The Future, Ertim Conservation Institute 